\title{
Sodium hypochlorite effects on dentin bond strength and acid-base resistant zone formation by adhesive systems
}

\author{
Marina Di Francescantonio ${ }^{1}$, Hamid Nurrohman², Tomohiro Takagaki², Toru Nikaido², \\ Junji Tagami², Marcelo Giannini ${ }^{1}$
}

${ }^{1}$ Universidade Estadual de Campinas - UNICAMP, Piracicaba Dental School, Department of Restorative Dentistry, Piracicaba, SP, Brazil

${ }^{2}$ Tokyo Medical and Dental University, Department of Cariology and Operative Dentistry, Tokyo, Japan

\begin{abstract}
Aim: To evaluate the effects of $10 \% \mathrm{NaOCl}$ gel application on the dentin bond strengths and morphology of resin-dentin interfaces formed by three adhesives. Methods: Two etch-and-rinse adhesives (One-Step Plus, Bisco Inc. and Clearfil Photo Bond, Kuraray Noritake Dental) and one self-etch adhesive (Clearfil SE Bond, Kuraray Noritake Dental) were applied on dentin according to the manufacturers' instructions or after the treatment with $10 \% \mathrm{NaOCl}$ (ED-Gel, Kuraray Noritake Dental) for $60 \mathrm{~s}$. For interfacial analysis, specimens were subjected to acid-base challenge and observed by SEM to identify the formation of the acid-base resistant zone (ABRZ). For microtensile bond strength, the same groups were investigated and the restored teeth were thermocycled (5,000 cycles) or not before testing. Bond strength data were subjected to two-way ANOVA and Tukey's test $(\mathrm{p}<0.05)$. Results: $\mathrm{NaOCl}$ application affected the bond strengths for One-Step Plus and Clearfil Photo Bond. Thermocycling reduced the bond strengths for Clearfil Photo Bond and Clearfil SE Bond when used after $\mathrm{NaOCl}$ application and One-Step Plus when used as recommended by manufacturer. ABRZ was observed adjacent to the hybrid layer for self-etch primer. The etch-and-rinse systems showed external lesions after acid-base challenge and no ABRZ formation when applied according to manufacturer's instructions. Conclusions: $10 \% \mathrm{NaOCl}$ changed the morphology of the bonding interfaces and its use with etch-\&-rinse adhesives reduced the dentin bond strength. Formation of ABRZ was material-dependent and the interface morphologies were different among the tested materials.
\end{abstract}

Keywords: dental bonding; dentin; dental caries susceptibility; dentin-bonding agents; sodium hypochlorite; scanning electron microscopy.

\section{Introduction}

Received for publication: November 17, 2015 Accepted: December 22, 2015

Correspondence to: Marcelo Giannini

Departamento de Odontologia Restauradora Faculdade de Odontologia de Piracicaba - UNICAMP

Av. Limeira, 901, Piracicaba, SP, Brasil CEP: $13414-903$

Phone: + 551921065340

Fax: + 551921065218

E-mail: giannini@fop.unicamp.br
The success and durability of restorations depends on the type of adhesive technique and materials used. The advancement of Adhesive Dentistry produces restorations with excellent aesthetic and mechanical properties; even so, the restorative procedures still present some clinical problems related to microleakage and degradation. Such problems could occur from gap formations between tooth and adhesive restoration, which can lead to secondary caries and fractures in adjacent dental structures, affecting the longevity of restorations ${ }^{1}$.

Many studies have evaluated the prevention and control of secondary caries around composite restorations, mainly in dentin. The focus of these investigations has been on e resin-adhesive interfaces after cariogenic challenge. Different methods 
can be used to analyze the effects of cariogenic challenge on dentin-resin interfaces, such as scanning electron microscopy (SEM), polarized light microscopy, microhardness analysis, microradiography, confocal laser scanning microscopy and X-ray analytical microscopy ${ }^{2-5}$. Tsuchiya et al. ${ }^{6}$ (2004) using SEM identified the formation of an acid-base resistant zone (ABRZ) beneath the hybrid layer, which was characterized by argon-ion etching technique. However, they reported that ABRZ was observed only for some categories of adhesive systems ${ }^{7}$.

Sodium hypochlorite $(\mathrm{NaOCl})$ is a well-known nonspecific proteolytic agent able to dissolve organic material and has been used in Restorative Dentistry as a deproteinizing agent for dentin ${ }^{8-10}$. The rationale for using $\mathrm{NaOCl}$ is that it facilitates the infiltration of adhesive resins into an etched dentin substrate, creating the bond without collagen fibrils and hybrid layer ${ }^{11-13}$. Depending on each test methodology and/or specific composition of dentin bonding agents, the application of $\mathrm{NaOCl}$ on acid etching may increase or decrease bond strengths ${ }^{14-19}$.

This in vitro study was conducted to determine by SEM the effects of thermocycling and $10 \% \mathrm{NaOCl}$ gel application after acid etching on the dentin bond strengths and resindentin interface morphology. The first tested hypothesis was that $10 \% \mathrm{NaOCl}$ and thermocycling would not reduce the dentin bond strength, regardless the type of adhesive system used. The second was that $10 \% \mathrm{NaOCl}$ application would not provide the ABRZ formation.

\section{Material and methods}

Eighty-four caries-free human third molars stored in an aqueous solution containing $0.2 \%$ thymol were used after approval by the Ethics Research Committee (process \# 90/ 2009). This study tested three adhesive systems : two etchand-rinse adhesive systems: One-Step Plus (Bisco Inc., Schaumburg, IL, USA) and Clearfil Photo Bond (Kuraray Noritake Dental, Tokyo, Japan); and one self-etch adhesive system: Clearfil SE Bond (Kuraray Noritake Dental). Table 1 displays the composition and lot number of these adhesive systems.
Bond strength test - Sixty teeth were used in this part of study $(n=5)$. The occlusal enamel of teeth was removed using a low speed diamond saw (Buehler, Lake Bluff, IL, USA) to expose a flat middle-depth coronal dentin surface. The exposed dentin surface was ground using 600-grit silicon carbide paper (Fuji Star, Sankyo Rikagaku, Saitama, Japan) under water-cooling. Adhesive systems were applied to the dentin surfaces according to the manufacturers' instructions or following $10 \% \mathrm{NaOCl}$ application (AD-Gel, Kuraray Noritake Dental). The experimental groups are described in Table 2.

When $10 \% \mathrm{NaOCl}$ was used with two acid-etch adhesives (One-Step Plus and Clearfil Photo Bond), it was applied for $1 \mathrm{~min}$ after phosphoric acid etching, rinsed for $20 \mathrm{~s}$ and gently air-dried for $10 \mathrm{~s}$, followed by adhesive application. For Clearfil SE Bond, $10 \% \mathrm{NaOCl}$ was used after SE-Primer. Afterwards, acetone (for $30 \mathrm{~s}$ ) and water rinsing (for $30 \mathrm{~s}$ ) were used to remove functional monomers that did not react with calcium ions from the dentin surface. Next, the Clearfil SE Bond bonding resin was applied to dentin and lightactivated for $10 \mathrm{~s}$ (Optilux 501, Demetron-Kerr Corp., Danbury, CT, USA).

A 6 mm-high composite block (Clearfil Majesty, Kuraray Noritake Dental, Tokyo, Japan and Aelite LS, Bisco Inc) was built-up incrementally over the bonded dentin. Three increments of $2.0 \mathrm{~mm}$ were placed and each layer was light activated for $20 \mathrm{~s}$. After $24 \mathrm{~h}$ in distilled water at $37{ }^{\circ} \mathrm{C}$, half of the stored specimens and the other halves were thermocycled 5,000 times in a water bath between $5{ }^{\circ} \mathrm{C}$ and $55{ }^{\circ} \mathrm{C}$ with a $30 \mathrm{~s}$ dwell time in each bath and a transfer time of $10 \mathrm{~s}$. Afterwards, the teeth were serially sectioned perpendicular to the adhesive-dentin interface in mesiodistal and buccal-lingual directions to obtain bonded beams of approximately $1.0 \mathrm{~mm}^{2}$ cross-sectional area using a slow-speed diamond saw. The specimens were tested individually by attaching them to a microtensile jig with cyanoacrylate glue (Model Repair II, Dentsply-Sankin, Tochiji, Japan). The bonded beams were tested in tension using a universal testing machine (EZ Test, Shimadzu Corp., Kyoto, Japan) at a $1.0 \mathrm{~mm} / \mathrm{min}$ crosshead speed.

The load in kgf and the bonding surface area of the specimen were recorded and microtensile bond strength data

Table 1. Composition and batch number of the adhesive systems used in this study (information supplied by the MSDS of each manufacturers).

Material $\quad$ Composition
One-Step
Plus

Clearfil Photo

Bond
Catalyst liquid: Bis-GMA, MDP, HEMA, hydrophobic dimethacrylate, benzoyl peroxide, camphorquinoneUniversal liquid: N,N'-diethanol p-toluidine, sodium benzene sulûnate, ethyl alcohol
Catalyst: 00453A

Universal:00549A

Primer:01633A

Adhesive: 01088B 
Table 2. Experimental groups and application technique for adhesive systems.

\begin{tabular}{lc}
\hline $\begin{array}{l}\text { Restorative System Treatment } \\
\text { (adhesive + composite) }\end{array}$ & Treatment \\
\hline One-Step Plus + Aelite LS & Manufacturer's Instructions \\
One-Step Plus + Aelite LS & $10 \% \mathrm{NaOCl}$ application \\
Clearfil Photo Bond + Majesty & Manufacturer's Instructions \\
Clearfil Photo Bond + Majesty & $10 \% \mathrm{NaOCl}$ application \\
Clearfil SE Bond + Majesty & Manufacturer's Instructions \\
Clearfil SE Bond + Majesty & Primer removal with acetone and \\
& water+ 10\% NaOCl application \\
\hline
\end{tabular}

were expressed in MPa. Statistical analysis was performed with statistical software (Minitab 15, Minitab, State College, PA, USA). Two-way analysis of variance (ANOVA) for the "restorative system" and "thermocycling" factors was performed, followed by a Tukey's post hoc test $(p<0.05)$.

The fractured surfaces of the tested specimens were sputter-coated with gold (MED 010, Balzers Union, Balzers, Liechtenstein) and examined using a scanning electron microscope (VP 435, Leo Electron Microscopy Ltd., Cambridge, UK). Failure patterns were classified as: (1) failure within adhesive resin layer; (2) failure within hybrid layer; (3) cohesive failure in dentin; and (4) mixed failure involving the adhesive resin and hybrid layer.

Acid-base resistant zone evaluation - The methodology for specimen preparation (Figure 1) followed a previous report ${ }^{20}$. Twenty-four caries-free human third molars were used in this part of study $(n=4)$. Teeth were prepared according to the bond strength methodology and the same application technique for adhesives and composites was used.

After bonding and composite placement, teeth were stored in distilled water at $37{ }^{\circ} \mathrm{C}$ for $24 \mathrm{~h}$ and then were vertically sectioned through the dentin-adhesive interface and embedded in an epoxy resin (Epoxicure Resin, Buehler). The embedded teeth were placed in $100 \mathrm{~mL}$ of a buffered demineralizing solution, containing $2.2 \mathrm{mmoL} / \mathrm{L} \mathrm{CaCl}, 2.2$ $\mathrm{mmoL} / \mathrm{L} \mathrm{NaH} \mathrm{PO}_{4}$ and $50 \mathrm{mmoL} / \mathrm{L}$ acetic acid $(\mathrm{pH} 4.5)$ for $90 \mathrm{~min}$ to create artificial recurrent $\mathrm{caries}^{20}$. After this, the teeth were immersed in $5 \% \mathrm{NaClO}$ for 20 min to remove any demineralized dentin collagen fibrils, followed by rinsing

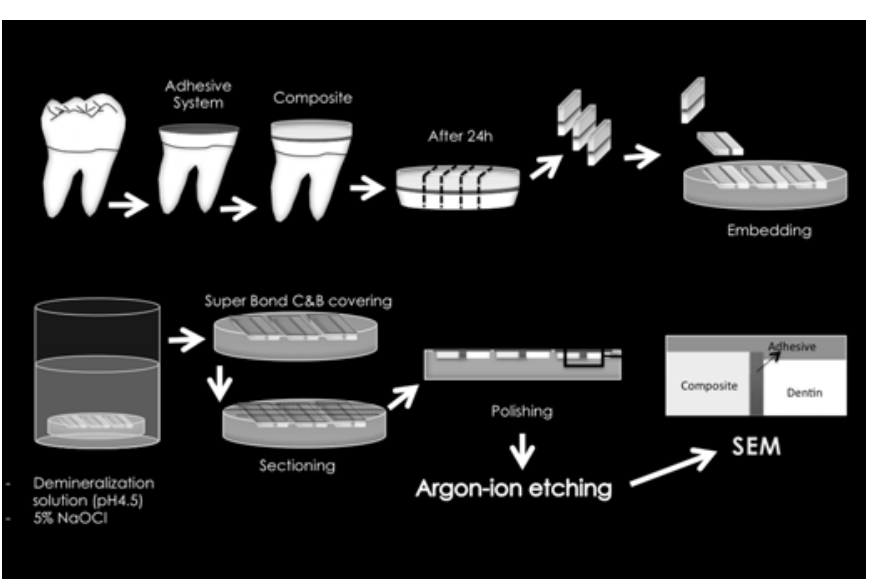

Fig. 1. Schematic illustration of the specimen preparation for SEM. with water for $30 \mathrm{~s}$. The 4-META/MMA-TBB resin (Super Bond C\&B, Sun Medical, Moriyama, Japan) was used as infiltrant agent to protect the demineralized surface during polishing procedure. After curing of infiltrant resin, the samples were vertically sectioned through the dentin-adhesive interface to obtain 1-mm thick specimens and then polished with diamond pastes (Struers A/S, Copenhagen, Denmark). The polished surfaces were conditioned with a beam of argonions (EIS-IE, Elionix Inc., Tokyo, Japan) for $6 \mathrm{~min}$. The operating conditions for argon ion beam etching were $1 \mathrm{kV}$ accelerating voltage and $0.2 \mathrm{~mA} / \mathrm{cm}^{2}$ current density with the ion beam positioned directly perpendicular to the polished surface. The specimens were gold-sputter coated and the morphological changes at the dentin-adhesive interfaces produced by acid-base challenge were observed by SEM (JSM-5310LV, Jeol, Tokyo, Japan).

\section{Results}

Bond strength - The dentin bond strength means of the experimental groups are shown in Table 3. Two-way ANOVA indicated that the "restorative system" and "thermocycling" factors influenced the bond strength results $(p<0.0001$ and $\mathrm{p}<0.0001$, respectively), and the interaction factor was also significant $(p=0.0004)$.

Dentin bond strengths of One-Step Plus and Clearfil Photo Bond decreased following $10 \% \mathrm{NaOCl}$ application $(p<0.05)$, while Clearfil SE Bond was not affected $(p>0.05)$. Thermocycling decreased the bond strength of Clearfil SE Bond after $\mathrm{NaOCl}$ application. Thermocycling affected also the bond strength of Clearfil Photo Bond (with or without $\mathrm{NaOCl}$ application) and One-Step Plus when following the manufacturer's instructions $(\mathrm{p}<0.05)$.

Table 4 shows de percentage distribution of failure modes. Failure within adhesive resin layer, within hybrid layer and mixed were observed for all experimental groups. In general, higher incidence of cohesive failure in dentin occurred when teeth bonded with Clearfil Photo Bond and Clearfil SE Bond were thermocycled.

Acid-base resistant zone - The SEM images of the dentinresin interfaces after acid-base challenge are shown in Figure 2. The outer lesion created by the acid challenge was observed in all groups; it was approximately 10 to 20 ìm thick. One-Step Plus and Clearfil Photo Bond used following the manufacturer's instructions formed thick hybrid layers of approximately 3 to $4 \mu \mathrm{m}$ (Figures $2 \mathrm{~A}$ and 2C). However, the hybrid layer formed by One-Step Plus was destroyed by acid-base challenge (Figure 2C) and wall lesions were observed for it and Clearfil Photo Bond adhesives. The etchand-rinse adhesives applied after $10 \% \mathrm{NaOCl}$ did not form hybrid layer. The adhesive resins were bonded to irregular dentin wall created by the acid etching and no wall lesion was found along the adhesive interface (Figures $2 \mathrm{~B}$ and 2D).

For Clearfil SE Bond, 2-ìm-thick ABRZ formation was observed (Figure 2E). A very thin ABRZ, approximately 0.5 ìm thick, was found with $10 \% \mathrm{NaOCl}$ treatment after 
Table 3. Mean dentin bond strengths (standard deviation) of restorative systems (composite and adhesive) after thermocycling (TC) or not (in MPa).

\begin{tabular}{lccc}
\hline Restorative system & $\mathrm{NaOCl}$ Treatment & Without TC & With TC \\
One-Step Plus and & no & $50.5(3.3) \mathrm{A} \mathrm{a}$ & $35.2(4.5) \mathrm{BCD}$ b \\
Aelite LS & yes & $38.0(3.4) \mathrm{C} \mathrm{a}$ & $32.4(2.7) \mathrm{D} \mathrm{a}$ \\
& & & \\
Clearfil Photo & no & $50.4(2.6) \mathrm{Aa}$ & $41.1(4.1) \mathrm{ABC} \mathrm{b}$ \\
Bondand Majesty & yes & $42.4(5.1) \mathrm{BC} \mathrm{a}$ & $34.5(3.2) \mathrm{CD} \mathrm{b}$ \\
& & $49.9(6.5) \mathrm{AB} \mathrm{a}$ & $44.2(6.0) \mathrm{A} \mathrm{a}$ \\
Clearfil SE Bond and & no & $44.1(6.0) \mathrm{ABC}$ a & $32.5(3.5) \mathrm{D} \mathrm{b}$ \\
Majesty & yes &
\end{tabular}

Capital letters compare "Restorative System/ $\mathrm{NaOCl}$ Treatment" within the same column. Lower case letters compare "Thermocycling or not" (row) for the same "Restorative System/ $\mathrm{NaOCl}$ Treatment".

Table 4. Failure modes distribution (\%) according to the experimental groups.

\begin{tabular}{llllll}
\hline Adhesive & / Treatment/ Thermocycling & $\mathbf{1}$ & $\mathbf{2}$ & $\mathbf{3}$ & $\mathbf{4}$ \\
One-Step Plus & / No treatment / None & 36 & 30 & 18 & 16 \\
& / No treatment / Thermocycled & 26 & 35 & 10 & 20 \\
& / 10\% sodium hypochlorite / None & 13 & 51 & 10 & 39 \\
& / 10\% sodium hypochlorite / Thermocycled & 12 & 40 & 10 & 38 \\
Clearfil Photo Bond & / No treatment / None & 23 & 25 & 0 & 52 \\
& / No treatment / Thermocycled & 12 & 24 & 12 & 51 \\
& / 10\% sodium hypochlorite / None & 14 & 37 & 12 & 37 \\
& / 10\% sodium hypochlorite / Thermocycled & 11 & 36 & 17 & 36 \\
Clearfil SE Bond & / No treatment / None & 34 & 24 & 0 & 62 \\
& / No treatment / Thermocycled & 24 & 28 & 6 & 62 \\
& / 10\% sodium hypochlorite / None & 19 & 36 & 10 & 35 \\
& / 10\% sodium hypochlorite / Thermocycled & 13 & 30 & 18 & 39 \\
\hline
\end{tabular}

1- failure within adhesive resin layer; 2- failure within hybrid layer; 3- cohesive failure in dentin; 4- mixed failure involving the adhesive resin and hybrid layer.

demineralization with the self-etch primer for Clearfil SE Bond (Figure 2F).

\section{Discussion}

The first tested hypothesis, that $10 \% \mathrm{NaOCl}$ and thermocycling would not reduce dentin bond strengths regardless the type of adhesive system used, was rejected because the dentin bond strengths of adhesives were reduced with $10 \% \mathrm{NaOCl}$ application and thermocycling. The second hypothesis stating that $10 \% \mathrm{NaOCl}$ application would not provide the ABRZ formation was also rejected, because the self-etch adhesive system formed ABRZ even with $\mathrm{NaOCl}$ application after etching.

Secondary caries and restorative material fractures have been considered as major causes for the failure of composite restorations ${ }^{1}$ and the same adhesive procedures seemed not providing restoration margins free of gaps and microleakage $^{21}$. Regarding caries progression in the dentin margins around adhesive restorations, the presence of ABRZ below the hybrid layer could protect dentin against recurrent caries attack. The ABRZ formation is related to penetration of adhesive monomers into the mineralized dentin, in which chemical interaction occurs between the 10-MDP functional monomer and hydroxyapatite ${ }^{22}$.

In this study, etch-and-rinse adhesive systems used according to the manufacturers' instructions showed external lesions adjacent to hybrid layer and no ABRZ formation was detected at dentin-resin interface after the acid-base challenge, which corroborates previous studies ${ }^{11-13}$. However, the hybrid layer disappeared and no erosion lesion was found at the interface after $10 \% \mathrm{NaOCl}$. The hybridization produced by etch-and-rinse adhesives is not a uniform layer, especially with respect to the existence of nanospaces within the hybrid layer, which correspond to dentin etched without monomer infiltration and filled with water or organic solvents ${ }^{23}$. When $10 \% \mathrm{NaOCl}$ was applied to etched dentin, the exposed collagen fibrils were removed and the adhesives were unable to penetrate into underlying dentin, which resulted in no hybrid layer formation ${ }^{11-13}$. However, it was possible to note that there was a good contact without gaps between adhesives and dentin.

For self-etch adhesive, a very thin hybrid layer is formed and after acid-base challenge, Clearfil SE Bond presented ABRZ approximately $2 \mathrm{~mm}$-thick. When the SE primer is applied on the dentin surface, this acidic primer demineralizes the smear layer on the surface and next the underlying dentin. MDP-containing self-etch primer is able to create two layers of demineralized dentin, one totally demineralized and another partially demineralized. Thus, when it is applied on mineralized dentin surface, a superficial demineralization 

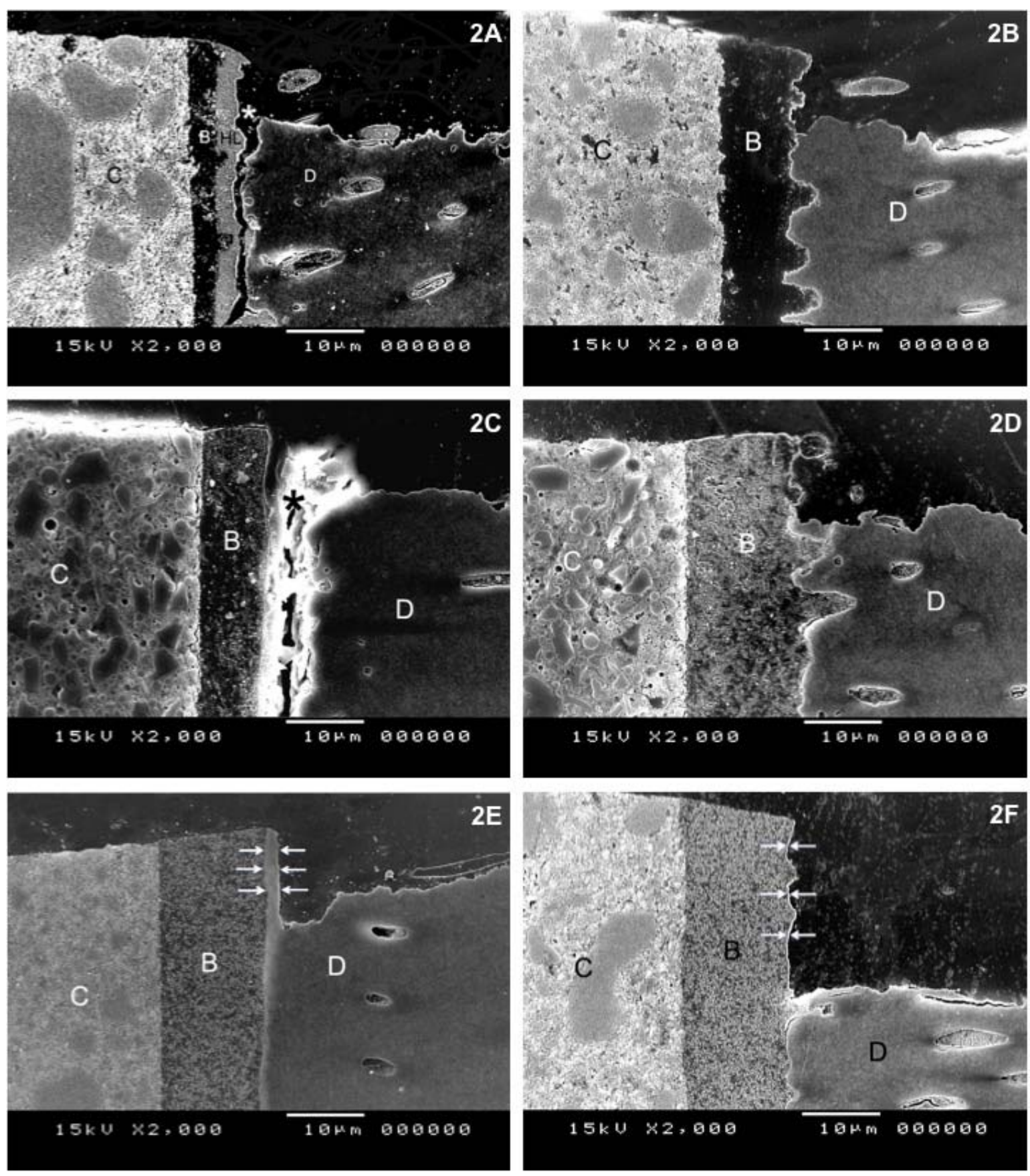

Fig. 2. SEM observations of the adhesive-dentin interfaces after acid-base challenge (x2.000). A- Clearfil Photo Bond, B- Clearfil Photo Bond applied after $10 \%$ NaOCl C- One-Step Plus, D- One-Step Plus applied after 10\% NaOCl, E- Clearfil SE Bond and F- Clearfil SE Bond/10\% NaOCl (C: composite; B: adhesive layer; HL: hybrid layer; D: dentin; *: hybrid layer destroyed; arrows: acid-base resistant zone).

around $1 \mathrm{~mm}$ deep is formed and adjacent dentin at the bottom is also affected, but it is partially demineralized and contains hydroxyapatite, where the MDP chemical interaction occurs ${ }^{24-25}$.

When dentin surface was treated with SE Primer, rinsed with acetone/water to remove the excess primer on the surface and treated with $10 \% \mathrm{NaOCl}$ to deplete the exposed collagen, a very thin, approximately $0.5 \mathrm{~mm}$-thick. ABRZ was observed. This very thin ABRZ formation at bottom (sub-surface region) was due to MDP-hydroxyapatite interaction with the remaining hydroxyapatite after collagen removal ${ }^{8-10}$.
Nurrohman, et al. ${ }^{26}$ (2012) using transmission electron microscopy detected $5 \mathrm{~mm}$ hybrid layer formation on demineralized dentin for Clearfil Photo Bond etch-and-rinse adhesive. They also evaluated the interaction between specific functional groups and apatite crystals and showed chemical bonding potential of $10-\mathrm{MDP}$ with the remaining crystals, which produced the ABRZ zone. Another study detected strong affinity of 10-MDP-based self-etch system to deproteinized dentin by formation of 10-MDP-Ca salt ${ }^{19}$.

The acid-base challenge destroyed the hybrid layer 
formed by One-Step Plus, while the hybrid layer remained intact for Clearfil Photo Bond. These results suggested that different qualities of hybridization promoted by etch-andrinse adhesive systems maybe caused by difference in the monomer compositions. One-Step Plus contains BPDM and HEMA monomers, while Clearfil Photo Bond presents HEMA and MDP, which contribute to monomer penetration into etched dentin and chemical interaction with hydroxyapatite at the bottom of the hybrid layer, respectively.

The application of $10 \% \mathrm{NaOCl}$ decreased the dentin bond strength for the tested etch-and-rinse adhesives. However, the results are rather controversial on this matter. While the findings of this study agree with the outcomes from some authors ${ }^{16-18}$, other studies reported no changes in dentin bond strength when $10 \% \mathrm{NaOCl}$ was used ${ }^{11,19}$. Conversely, some reports showed that the treatment of etched dentin with $10 \% \mathrm{NaOCl}$ is beneficial, depending on the adhesive system evaluated ${ }^{12-15}$. These inconsistent outcomes in the literature hindered a widespread use of this technique.

Besides, deproteinization with $5 \% \mathrm{NaOCl}$ removes collagen from demineralized dentin and also exposes lateral secondary tubules at the intertubular region and peritubular area $^{12}$. According to Prati et al. ${ }^{13}$ (1999), treatment of etched dentin with $\mathrm{NaOCl}$ produced an unusual type of resin infiltration of mineralized dentin, which may explain the mechanism of resin bonding to $\mathrm{NaOCl}$-treated dentin. A previous study also reported significant reduction in bond strength to dentin after thermocycling for some adhesives, independent whether they were applied on deproteinized dentin or not $^{19}$.

Because $10 \% \mathrm{NaOCl}$ removes collagen fibrils ${ }^{8-10}$, the bonding is formed in absence of collagen fibrils and only by the contact between adhesive monomer and dentin ${ }^{11-13}$. Thus, it was suggested that the only artificial material at the interface, the polymer formed after light activation of adhesives, could undergo degradation depending on monomeric composition, resulting in decrease of bond strength. Some hydrophilic monomer resins, such as those in the current adhesives are highly prone to absorb water ${ }^{27}$. Since adhesives used in the present study contain high concentration of hydrophilic monomers such as HEMA, water sorption of these monomers could contribute to bond strength reduction. In addition, residual water entrapped at the deepest regions of demineralized and/or deproteinized dentin forms poorly polymerized polymer chains ${ }^{28}$, which are weaker and less stable over time than those formed in absence of moisture.

The failure patterns related for each group depended on the adhesive system used and $\mathrm{NaOCl}$ treatment. After thermocycling, a slightly higher percentage of cohesive dentin failure was reported, suggesting degradation of the collagen matrix of dentin or monomeric components of the adhesive systems infiltrated in dentin.

Secondary caries can initiate at defects, like gaps in the marginal areas of restorations. The self-etch primer system used in this study demonstrated good dentin bonding performance and sealing ability, and also resistance against the acid-base challenge $\mathrm{e}^{6,20,22,29-30}$. Therefore, formation of an
ABRZ is important for the control of secondary caries around restoration, but this effect depends on the type of adhesive system $^{7,22}$. The application of $10 \% \mathrm{NaOCl}$ changed the demineralization pattern around composite restoration, because there was no hybrid layer formation. The bond strength of One-Step Plus etch-and-rinse adhesive to sodium hypochlorite-treated dentin did not reduce with thermocycling even without the hybrid layer. However, the use of $10 \% \mathrm{NaOCl}$ represents an extra step and may not assure a superior bonding performance when dentin deproteinization is performed after acid etching.

Within the limitations of this study, the following conclusions were drawn: 1- the application of $10 \% \mathrm{NaOCl}$ after acid etching did not improve the bond strength to dentin neither after thermocycling; 2- ABRZ formation is materialdependent.

\section{References}

1. Demarco FF, Corrêa MB, Cenci MS, Moraes RR, Opdam NJ. Longevity of posterior composite restorations: not only a matter of materials. Dent Mater. 2012; 28: 87-101.

2. Carvalho FG, Puppin-Rontani RM, Soares LE, Santo AM, Martin AA, Nociti-Junior FH. Mineral distribution and CLSM analysis of secondary caries inhibition by fluoride/ MDPB-containing adhesive system after cariogenic challenges. J Dent. 2009; 37: 307-14.

3. Pinto CF, Vermelho PM, Aguiar TR, Paes Leme AF, Oliveira MT, Souza EM et al. Enamel and dentin bond strength, interfacial ultramorphology and fluoride ion release of self-etching adhesives during a pH-cycling regime. J Adhes Dent. 2015; 17: 27-34.

4. Kuper NK, van de Sande FH, Opdam NJ, Bronkhorst EM, de Soet JJ, Cenci MS et al. Restoration materials and secondary caries using an in vitro biofilm model. J Dent Res. 2015; 94: 62-8.

5. Almeida Ayres AP, Tabchoury CP, Bittencourt Berger S, Yamauti M, Bovi Ambrosano GM, Giannini M. Effect of Fluoride-containing Restorative Materials on Dentin Adhesion and Demineralization of Hard Tissues Adjacent to Restorations. JAdhes Dent. 2015; 17: 337-45.

6. Tsuchiya S, Nikaido T, Sonoda H, Foxton RM, Tagami J. Ultrastructure of the dentin-adhesive interface after acid-base challenge. JAdhes Dent. 2004; 6: $183-90$.

7. Nikaido T, Nurrohman H, Takagaki T, Sadr A, Ichinose S, Tagami J. Nanoleakage in Hybrid Layer and Acid-Base Resistant Zone at the Adhesive/ Dentin Interface. Microsc Microanal. 2015; 21: 1271-7.

8. Tartari T, de Almeida Rodrigues Silva e Souza P, Vila Nova de Almeida B, Carrera Silva Júnior JO, Facíola Pessoa O, Silva e Souza Junior MH. A new weak chelator in endodontics: effects of different irrigation regimens with etidronate on root dentin microhardness. Int J Dent. 2013; 2013: 743018.

9. Gowda L, Das UM. Effect of various concentrations of sodium hypochlorite on primary dentin: an in vitro scanning electron microscopic study. J Clin Pediatr Dent. 2012; 37: 37-43

10. Sakae $\mathrm{T}$, Mishima $\mathrm{H}$, Kozawa $\mathrm{Y}$. Changes in bovine dentin mineral with sodium hypochlorite treatment. J Dent Res. 1988; 67: 1229-34.

11. Vargas MA, Cobb DS, Armstrong SR. Resin-dentin shear bond strength and interfacial ultrastructure with and without a hybrid layer. Oper Dent. 1997; 22: 159-66.

12. Perdigao J, Thompson JY, Toledano M, Osorio R. An ultra-morphological characterization of collagen-depleted etched dentin. Am J Dent. 1999; 12 : 250-5.

13. Prati $\mathrm{C}$, Chersoni $\mathrm{S}$, Pashley $\mathrm{DH}$. Effect of removal of surface collagen fibrils on resin-dentin bonding. Dent Mater. 1999; 15: 323-31.

14. Inai N, Kanemura N, Tagami J, Watanabe LG, Marshall SJ, Marshall GW. 
Adhesion between collagen depleted dentin and dentin adhesive. Am J Dent. 1998; 11: 123-7.

15. Kanca J, Sandrik J. Bonding to dentin. Clues to the mechanism of adhesion. Am J Dent. 1998; 11: 154-9.

16. De Castro AK, Hara AT, Pimenta LA. Influence of collagen removal on shear bond strength of one-bottle adhesive systems in dentin. J Adhes Dent. 2000; 2: 271-7.

17. Perdigao J, Lopes M, Geraldeli S, Lopes GC, Garcia-Godoy F. Effect of a sodium hypochlorite gel on dentin bonding. Dent Mater. 2000; 16: 311-23.

18. Uceda-Gomez N, Reis A, Carrilho MRO, Loguercio AD, Rodrigues Filho LE. Effect of sodium hypochlorite on the bond strength of an adhesive system to superficial and deep dentin. J Appl Oral Sci. 2003; 11: 223-8.

19. Zhou L, Wang Y, Yang H, Guo J, Tay FR, Huang C. Effect of chemical interaction on the bonding strengths of self-etching adhesives to deproteinized dentine. J Dent. 2015; 43: 973-80.

20. Inoue G, Tsuchiya S, Nikaido T, Foxton RM, Tagami J. Morphological and mechanical characterization of the acid-base resistant zone at the adhesivedentin interface of intact and caries-affected dentin. Oper Dent. 2006; 31 : 466-72.

21. Makishi, P, Shimada, Y, Sadr, A, Tagami, J, and Sumi, Y. Non-destructive 3D imaging of composite restorations using optical coherence tomography: marginal adaptation of self-etch adhesives. J Dent. 2011; 39: 316-25.

22. Nikaido T, Inoue G, Takagaki T, Waidyasekera K, lida Y, Shinohara MS et al. New strategy to create "Super Dentin" using adhesive technology: Reinforcement of adhesive-dentin interface and protection of tooth structures. Japan Dent Sci Rev. 2011; 47: 31-42.

23. Ferreira JC, Pires PT, Azevedo AF, Oliveira SA, Melo PR, Silva MJ. Influence of solvents and composition of etch-and-rinse and self-etch adhesive systems on the nanoleakage within the hybrid layer. J Contemp Dent Pract. 2013; 14: 691-9.

24. Yoshihara K, Yoshida Y, Hayakawa S, Nagaoka N, Irie M, Ogawa T et al. Nanolayering of phosphoric acid ester monomer on enamel and dentin. Acta Biomater. 2011; 7: 3187-95.

25. Fujita K, Ma S, Aida M, Maeda T, Ikemi T, Hirata M et al. Effect of reacted acidic monomer with calcium on bonding performance. J Dent Res. 2011; 90: 607-12.

26. Nurrohman H, Nikaido T, Takagaki T, Sadr A, Ichinose S, Tagami J. Apatite crystal protection against acid-attack beneath resin-dentin interface with four adhesives: TEM and crystallography evidence. Dent Mater. 2012; 28: 89-98.

27. Feitosa VP, Sauro S, Ogliari FA, Yoshihara K, Zanchi CH, Correr-Sobrinho L et al. Impact of hydrophilicity and length of spacer chains on the bonding of functional monomers. Dent Mater. 2014; 30: e317-23.

28. Toledano M, Cabello I, Yamauti M, Giannini M, Aguilera FS, Osorio E et al. Resistance to degradation of resin-dentin bonds produced by one-step self-etch adhesives. Microsc Microanal. 2012; 18: 1480-93.

29. Inoue $G$, Nikaido T, Foxton RM, Tagami J. The acid-base resistant zone in three dentin bonding systems. Dent Mater J. 2009; 28: 717-21.

30. Takagaki T, Nikaido T, Tsuchiya S, Ikeda M, Foxton RM, Tagami J. Effect of hybridization on bond strength and adhesive interface after acid-base challenge using 4-META/MMA-TBB resin. Dent Mater J. 2009; 28: 185-93. 